удк 366.1

Е.Б. Кметь ${ }^{1}$

А.Е. Новикова ${ }^{2}$

Владивостокский государственный университет экономики и сервиса

Владивосток. Россия

\title{
Методика исследования особенностей медиапредпочтений и медиаповедения в социальных сетях потребителей разных категорий товаров
}

\begin{abstract}
Поведение пользователей в социальных сетях непрерывно меняется, в связи с чем бизнесу необходимо отслеживать изменения поведения потребителей своих товаров для разработки эффективного продвижения. Методика исследования особенностей медиаповедения и медиапредпочтений в социальных сетях потребителей различных категорий товаров включает такие элементы, как характеристика методов и технологий сбора и анализа данных; процесс реализации методики с описанием каждого этапа; формулировка гипотез о наличии взаимосвязи между медиаповедением и медиапредпочтениями потребителей в социальных сетях и их интересом к разным категориям товаров; технология проверки гипотез и обработки результатов опроса в статпакете SPSS; алгоритм разработки комплекса предложений по продвижению определенных категорий товаров в социальных сетях. Методика представляет интерес и применима для любого бизнеса, специализирующегося на определенной категории товара, протестирована на основе эмпирического исследования в форме опроса, результаты которого позволили разработать комплекс предложений по продвижению в социальных сетях для лидеров рейтинга популярности товаров, приобретаемых в Интернете. Комплекс предложений сформирован посредством выделения в медиаповедении и медиапредпочтениях потребителей в социальных сетях ядра (совокупности параметров, единых для потребителей всех товаров) и специфических особенностей, доминирующих в характеристике поведения потребителей только определенной категории товара.
\end{abstract}

1 Кметь Елена Борисовна - канд. экон. наук, доцент кафедры международного маркетинга и торговли; e-mail: kmeteb@yandex.ru

2 Новикова Алена Евгеньевна - бакалавр 4 курса направления подготовки «Торговое дело», профиль «Маркетинг в торговой деятельности»; e-mail: novikova27.11.99@mail.ru 
Ключевые слова и словосочетания: медиаисследования, медиаповедение, медиапредпочтения, исследования в области продвижения, социальные сети, эффективность продвижения.

E.B. Kmet

A.E. Novikova

Vladivostok State University of Economics and Service

Vladivostok. Russia

\title{
Methodology for researching the characteristics of media preferences and media behavior in social networks of consumers of different categories of goods
}

\begin{abstract}
User behavior in social networks is constantly evolving, and businesses need to track changes in consumer behavior of their products in order to develop effective promotion. The research methodology of the peculiarities of media behavior and media preferences in social networks of consumers of various categories of goods includes such elements as: characteristics of methods and technologies for collecting and analyzing data; research process with a description of each stage; formulation of hypotheses about the existence of a relationship between media behavior and media preferences of consumers in social networks and their interest in different categories of goods; technology for testing hypotheses and processing survey results in the SPSS statistical package; an algorithm for developing a set of proposals for the promotion of certain categories of goods in social networks. The technique is of interest and is applicable to any business specializing in a certain category of goods. The methodology was tested on the basis of empirical research in the form of a survey, the results of which made it possible to develop a set of proposals for promotion in social networks for the leaders in the popularity rating of goods purchased on the Internet. The complex of proposals is formed on the basis of the selection in the media behavior and media preferences of consumers in social networks of the core (a set of parameters that are common for consumers of all goods) and specific features that dominate in the characteristics of consumer behavior only for a certain category of goods.
\end{abstract}

Keywords: media research, media behavior, media preferences, research in the field of promotion, social networks, promotion efficiency.

\section{Введение}

Социальные сети стали неотъемлемой частью жизни людей и успешными площадками для бизнеса. В социальных медиа пользователи знакомятся, общаются, развлекаются, ищут информацию о товарах, проводят достаточно большое количество времени ежедневно и совершают покупки. Соответственно, эти площадки оказывают огромное влияние не только на поведение людей в социуме, но и на лояльность к компаниям, брендам и продуктам, вносят весомый вклад в формирование спроса на товары. Владея большими данными о поведении своих пользователей, социальные сети предоставляют бизнесу возможности для анализа мнений, настройки таргетированной рекламы и выстраивания отношений 
Е.Б. Кметь, А.Е. Новикова. Методика исследования особенностей медиапредпочтений...

с клиентами [12]. Большие данные, собранные через социальные сети, не только стали ценным исследовательским инструментом, но и создали риски слежки и манипуляций [11].

Как и всё в этом мире, поведение пользователей в социальных сетях непрерывно развивается, эволюционирует, а бизнесу необходимо периодически отслеживать эти изменения для разработки эффективного продвижения. Для мониторинга этих изменений применяются эмпирические исследования в форме опроса.

Существует широкий спектр исследований в области продвижения, среди которых особое внимание заслуживают медиаисследования [9]. К этому направлению относят исследования коммуникационных возможностей рекламного рынка и исследования медиаповедения и медиапредпочтений потребителей определенных товаров и услуг [2].

Целью данной статьи является разработка методики исследования особенностей медиаповедения и медиапредпочтений потребителей разных категорий товаров в социальных сетях.Рассматриваемая методика представляет интерес и применима для любого бизнеса, специализирующегося на конкретной категории товаров.

\section{Предмет исследования, источниковая база исследования, противоречия в имеющихся исследованиях и авторская позиция}

На медиаисследованиях, связанных с медиаизмерениями и исследованиями средств массовой информации и их аудиторий, специализируются такие крупные компании, как Ipsos Comcon, Медиаскоп (Mediascope), Фонд Общественное Мнение (ФОМ). Синдикативные панельные исследовательские проекты являются востребованными в рамках медиакампаний и позволяют выстроить грамотную стратегию выбора востребованного контента, монетизации.

Предметом нашего исследования выступают особенности медиапредпочтений и медиаповедения в социальных сетях потребителей разных категорий товаров. Ocтановимся подробнее на предпосылках разделения медиапредпочтений и медиаповедения.

В широком смысле медиаповедение трактуется как система психических, физических и социальных действий индивида или сообщества, сложившаяся в результате их взаимодействия с медиасредой, направленная на самореализацию личности и удовлетворение ее информационных и коммуникативных потребностей [1].

В медиаповедении потребителей в социальных сетях принято выделять типы (или модели) поведения. В зависимости от характера действий различают активное поведение (размещение информации, загрузка фотографий, общение с другими, лайки, комментирование) и пассивное (просмотр или наблюдение за контентом, созданным другими) [10; 18]. В более сложных классификациях типов медиаповедения по отношению к источнику информации и степени активности выделяют активное, реактивное и индифферентное [1]. В разрезе двух сквозных параметров (пользователь-отправитель и двухстороннее взаимодействие) выделяют четыре типа поведения в социальных сетях: интерактивное, реактивное, трансляция чужого контента и пассивное [14]. Кроме этого, существуют меры поведения, связанные с объемом потребления на всех платформах соци- 
альных сетей (время и частота использования), они универсальны для всех социальных медиа $[14 ; 15]$.

Существует понятие медиапредпочтений. В широком смысле потребительские предпочтения - это социально и личностно детерминированное позитивное отношение потребителя к товару или его атрибутам, определяющее их выбор из ряда подобных. Соответственно, медиапредпочтения в социальных сетях - это позитивное отношение потребителей информации к определенному набору социальных сетей и атрибутам, определяющим их выбор из ряда подобных [6; 14]. Набор атрибутов охватывает отношение к местам покупки товаров, к типам контента, к видам и форматам рекламы $[7 ; 16]$. Визуализация медиапредпочтений потребителей информации проводится в форме построения графиков-рейтингов.

Медиаисследования пользователей социальных сетей проводятся для потребителей определенных категорий товаров, следовательно, в них целесообразно выделять следующие направления анализа: исследование медиаповедения и медиапредпочтений потребителей в социальных сетях. Исследование медиаповедения потребителей товаров в социальных сетях должно охватывать измерение характера их действий, степени активности, объемов потребления, степени влияния рекламы на принятие покупательского решения. Исследование медиапредпочтений должно быть направлено на выявление позитивного отношения к местам покупок в Интернете, к определенным социальным сетям и мессенджерам, к типам контента, к форматам и видам рекламы в социальных сетях [8].

Множество работ посвящено оценке влияния рекламы в социальных сетях на намерение пользователя совершить покупку и изучению отношения и поведенческой реакции клиентов (доверие к рекламе, уклонение от рекламы, скептицизм к рекламе и поведенческие намерения) [3; 5;13; 17].

Автор придерживается позиции, что в медиапредпочтениях и медиаповедении потребителей разных категорий товаров присутствуют две составляющие:

1) ядро - устойчивые, единые параметры (черты) для потребителей всех товаров;

2) специфические особенности, продиктованные особенностью категории товара.

Разным товарам соответствуют определенные типы покупательского поведения, продиктованные либо степенью вовлеченности в покупательский процесс и различиями между марками, либо усилиями по поиску информации и частотой покупки [4].

\section{Методы исследования, методологические принципы и инструменты, методика исследования}

Сбор данных осуществлялся посредством полевых количественных исследований в форме опроса респондентов по технологии Computer Assisted Web Interview (далее - CAWI) на сайте опросов ianketa.ru. Для анализа данных применялись статистические методы анализа (частотный анализ для одновариантных вопросов и множественный, корреляционный анализы для выявления силы, направления и характера зависимости). 
Предлагаемая методика включает следующие элементы:

- характеристика методов и технологий сбора и анализа данных;

- процесс реализации методики с описанием каждого этапа;

- формулировка гипотез о наличии взаимосвязи между медиаповедением и медиапредпочтениями потребителей в социальных сетях и их интересом к разным категориям товаров;

- технология проверки гипотез и обработки результатов опроса в статпакете SPSS;

- алгоритм разработки комплекса предложений по продвижению определенных категорий товаров в социальных сетях.

Процесс реализации методики исследования особенностей медиапредпочтений и медиаповедения потребителей разных категорий товаров в социальных сетях представлен на рисунке.

\section{Этап 1. Разработка инструментария полевого исследования}

•1.1 Контент-анализ научных публикаций и практического опыта публичных компаний в области исследования

-1.2 Определение совокупности данных, необходимых для анализа особенностей поведения потребителей разных категорий товаров в социальных сетях

• 1.3 Выдвижение гипотез о наличии взаимосвязи между медиаповедением и медиапредпочтениями потребителей в социальных сетях и их интересом к разным категориям товаров

• 1.4 Разработка технического задания на исследование и моделирование вопросов для анкеты

•1.5 Разработка технологии статистического анализа данных в SPSS

\section{Этап 2. Сбор данных}

•2.1 Кодирование анкеты на сервисе опросов ianketa.ru и генерирование ссылки на анкету

•2.2 Проведение опроса путем рассылки ссылки на онлайн-анкету респондентам •2.3 Контроль качества результатов опроса

\section{Этап 3. Анализ данных}

•3.1 Открытие файла с ответами с ianketa.ru (файл xls) в SPSS, кодировка значений ответов

•3.2 Описательный анализ (частотный анализ) для одновариантных и множественных вопросов анкеты

•3.3 Проверка (подтверждение или опровержение) выдвинутых гипотез о наличии взаимосвязи между переменными на основе расчета Хи-квадрата Пирсона $\left(\chi^{2}\right)$

\section{Этап 4. Характеристика особенностей медиапредпочтений и медиаповедения} потребителей разных категорий товаров в социальных сетях

•4.1 Формулировка общего ядра медиапредпочтений и медиаповедения потребителей разных категорий товаров в социальных сетях

•4.2 Формулировка особенностей медиапредпочтений и медиаповедения потребителей разных категорий товаров в социальных сетях

-4.3 Определение портрета сегментов потребителей разных категорий товаров в социальных сетях

•4.4 Разработка комплекса предложений по продвижению разных категорий товаров в социальных сетях

Рисунок. Процесс реализации методики исследования особенностей медиапредпочтений и медиаповедения в социальных сетях потребителей разных категорий товаров 
В таблице 1 представлены гипотезы о наличии взаимосвязи между медиаповедением и медиапредпочтениями потребителей в социальных сетях и их интересом к разным категориям товаров, выдвинутые по результатам контентанализа научных публикаций и исследования опыта продвижения публичных компаний в социальных сетях. Данные гипотезы предстоит подтвердить или опровергнуть на основе углубленного анализа результатов эмпирического полевого исследования с помощью методов статистического анализа, реализованных в статпакете SPSS.

Таблий 1

\section{Сигналы и гипотезы о наличии взаимосвязи между медиаповедением и медиапредпочтениями потребителей в социальных сетях и их интересом к разным категориям товаров}

\begin{tabular}{|c|c|}
\hline Сигналы & Гипотезы \\
\hline $\begin{array}{l}\text { Медиаповедение - это система психиче- } \\
\text { ских, физических и социальных действий } \\
\text { индивида или сообщества, сложившаяся в } \\
\text { результате их взаимодействия с медиасре- } \\
\text { дой [1], а медиапредпочтения в социальных } \\
\text { сетях - это позитивное отношение потреби- } \\
\text { телей информации к определенному набору } \\
\text { социальных сетей и атрибутам, определяю- } \\
\text { щим их выбор из ряда подобных [6; } 14]\end{array}$ & $\begin{array}{l}\text { Н1: В медиапредпочтениях и медиаповедении } \\
\text { потребителей разных категорий товаров присут- } \\
\text { ствуют устойчивые, единые черты для всех то- } \\
\text { варов - устойчивое ядро и специфические осо- } \\
\text { бенности, продиктованные спецификой катего- } \\
\text { рии товара }\end{array}$ \\
\hline $\begin{array}{l}\text { Существуют меры (показатели), которые } \\
\text { универсальны для всех платформ социаль- } \\
\text { ных сетей и основаны на поведенческих } \\
\text { данных, полученных с платформ социаль- } \\
\text { ных сетей [14] }\end{array}$ & $\begin{array}{l}\text { Н2: К ядру медиаповедения потребителей в со- } \\
\text { циальных сетях относятся следующие парамет- } \\
\text { ры: частота покупок, количество часов в день, } \\
\text { проводимых в социальных сетях, источники } \\
\text { информации о товарах в социальных сетях }\end{array}$ \\
\hline $\begin{array}{l}\text { Каждый пользователь демонстрирует ус- } \\
\text { тойчивый тип поведения в социальных се- } \\
\text { тях с присущим ему определенным характе- } \\
\text { ром действий [15] }\end{array}$ & $\begin{array}{l}\text { Н3: К особенностям медиаповедения потребите- } \\
\text { лей в социальных сетях относятся следующие } \\
\text { параметры: характер действий, отношение к } \\
\text { источнику информации и степени активности, } \\
\text { причины использования социальных сетей }\end{array}$ \\
\hline $\begin{array}{l}\text { Предпочтения связаны с местами соверше- } \\
\text { ния онлайн-покупок и силой влияния рек- } \\
\text { ламы на принятие покупательского решения } \\
\text { [6] }\end{array}$ & $\begin{array}{l}\text { Н4: К ядру медиапредпочтений потребителей в } \\
\text { социальных сетях относятся следующие пара- } \\
\text { метры: площадки совершения покупки, сила } \\
\text { влияния рекламы в социальных сетях на приня- } \\
\text { тие решения о покупке товара }\end{array}$ \\
\hline $\begin{array}{l}\text { Медиапредпочтения связаны с позитивным } \\
\text { отношением к определенным социальным } \\
\text { сетям, типам контента, видам и форматам } \\
\text { рекламы [3] }\end{array}$ & $\begin{array}{l}\text { Н5: К особенностям медиапредпочтений потре- } \\
\text { бителей в социальных сетях относятся следую- } \\
\text { щие параметры: набор используемых и попу- } \\
\text { лярных социальных сетей и мессенджеров, } \\
\text { предпочитаемый тип контента, виды и форматы } \\
\text { рекламы }\end{array}$ \\
\hline
\end{tabular}

Примечание: разработано авторами. 
Е.Б. Кметь, А.Е. Новикова. Методика исследования особенностей медиапредпочтений...

После выдвижения гипотез был разработан инструментарий полевого исследования (техническое задание на исследование и анкета). Анкета включала 25 вопросов, из которых пять последних являлись одновариантными и позволяли описать портрет респондентов (гендерную и возрастную структуру, уровень образования, род деятельности и материальное положение). Первый фильтрующий вопрос анкеты отсеял респондентов, не совершающих покупки в Интернете. Соответственно, остальные вопросы предназначались для проверки выдвинутых гипотез.

Описать ядро медиаповедения позволяли пять вопросов (далее приводятся номер и формулировка вопроса): 2. «Как часто Вы совершаете покупки товаров в Интернете?»; 3. «Укажите причины, по которым Вам нравится совершать покупки в Интернете»; 6. «Пользуетесь ли Вы социальными сетями и мессенджерами?»; 9. «Сколько в среднем часов в день Вы проводите в социальных сетях?»; 10. «Укажите основные причины использования Вами социальных сетей». Проанализировать особенности медиаповедения позволяли три вопроса: 11. «Укажите утверждения, характеризующие Ваше поведение в социальных сетях»; 15. «Укажите категории товаров, информацию о которых Вы чаще всего ищете в социальных сетях»; 16. «В каких социальных сетях Вы чаще всего ищете информацию о товарах?».

Описать ядро медиапредпочтений позволяли пять вопросов: 5. «Где Вы чаще всего совершаете покупки в Интернете?»; 13. «Ищете ли Вы в социальных сетях информацию о товарах?»; 14. «Какой источник информации в социальных сетях Вы используете для поиска информации о товарах?»; 17. «Как Вы относитесь к рекламе в социальных сетях?»; 20. «Влияет ли реклама в социальных сетях на Ваше решение о приобретении товаров?».

Проанализировать особенности медиапредпочтений позволяли шесть вопросов: 4. «Какие категории товаров Вы чаще всего приобретаете в Интернете?»; 7. «Какими социальными сетями и мессенджерами Вы пользуетесь?»; 8. «Какие из используемых социальных сетей и мессенджеров Вам нравятся больше всего?»; 12. «Какой тип контента Вы чаще всего просматриваете в социальных сетях?»; 18. «Какой формат рекламы в социальных сетях кажется Вам наиболее предпочтительным?»; 19. «Какой тип рекламы в социальных сетях кажется Вам наиболее предпочтительным?».

Технология реализации анализа в SPSS на третьем этапе (шаги 3.2 и 3.3 ) представлена в табл. 2.

Таблица 2

Технология реализации анализа в SPSS на третьем этапе процесса исследования (шаги 3.2 и 3.3)

\begin{tabular}{|l|l|l|}
\hline \multicolumn{1}{|c|}{ Шаги анализа } & \multicolumn{1}{|c|}{$\begin{array}{c}\text { Статистические процедуры анализа в SPSS } \\
\text { и команды меню }\end{array}$} & \multicolumn{1}{|c|}{ Визуализация } \\
\hline 3.2 Описательный (частотный) анализ для одновариантных и множественных вопросов анкеты \\
\hline $\begin{array}{l}\text { - Структура ответов на } \\
\text { одновариантные вопросы }\end{array}$ & $\begin{array}{l}\text { Построение линейных распределений по } \\
\text { каждому вопросу. } \\
\text { Команда главного меню Ана- } \\
\text { лиз/Onисательные статистики/Чaстоты } \\
\text { (Analyze/Frequencies) }\end{array}$ & $\begin{array}{l}\text { Круговые диа- } \\
\text { граммы, построен- } \\
\text { ные по доле рес- } \\
\text { пондентов }\end{array}$ \\
\hline
\end{tabular}


Окончание табл. 2

\begin{tabular}{|c|c|c|}
\hline Шаги анализа & $\begin{array}{c}\text { Статистические процедуры анализа в SPSS } \\
\text { и команды меню }\end{array}$ & Визуализация \\
\hline $\begin{array}{l}\text { - Рейтинги и ТОПы для } \\
\text { ответов на вопросы }\end{array}$ & $\begin{array}{l}\text { 1. Создание многовариантных переменных } \\
\text { (или наборов множественных ответов) для } \\
\text { множественного вопроса с возможностью } \\
\text { выбора нескольких вариантов ответа. } \\
\text { Команда меню Анализ/Множественные от- } \\
\text { веты/Создать множественные наборы } \\
\text { (Analyze/Multiple Response/Define Variable } \\
\text { Sets...). } \\
\text { 2. Построение линейных распределений для } \\
\text { множественных ответов по каждому вопросу. } \\
\text { Команда главного меню Aнализ/Создать } \\
\text { многовариантную переменную/Чacmoть } \\
\text { (Analyze/Multiple Response/Frequencies) }\end{array}$ & $\begin{array}{l}\text { Линейчатые (стол- } \\
\text { биковые) диаграм- } \\
\text { мы, построенные } \\
\text { по доле респон- } \\
\text { дентов }\end{array}$ \\
\hline \multicolumn{3}{|c|}{$\begin{array}{l}\text { 3.3. Проверка (подтверждение или опровержение) выдвинутых гипотез о наличии взаимосвязи } \\
\text { между переменными на основе расчета Хи-квадрата Пирсона }\left(\chi^{2}\right)\end{array}$} \\
\hline $\begin{array}{l}\text { - Выявление зависимо- } \\
\text { сти между предпочте- } \\
\text { ниями к приобретаемым } \\
\text { товарным категориям и } \\
\text { переменными, характе- } \\
\text { ризующими медиапред- } \\
\text { почтения и медиапове- } \\
\text { дение пользователей }\end{array}$ & $\begin{array}{l}\text { 1. Создать наборы множественных ответов } \\
\text { для всех множественных вопросов с возмож- } \\
\text { ностью выбора нескольких вариантов ответа. } \\
\text { Команда меню Анализ/Настраиваемые таб- } \\
\text { лицы//Haборы множественных ответов } \\
\text { (Analyze/Tables/Multiple Response Sets). } \\
\text { 2. Построить таблицы сопряженности (Custom } \\
\text { Tables) попарно между наборами множествен- } \\
\text { ных ответов, описывающих медиаповедение и } \\
\text { медиапредпочтения потребителей, и интересом } \\
\text { респондентов к разным категориям товаров. } \\
\text { Команда меню Анализ/Настраиваемые таб- } \\
\text { лицьь (Апаlуzе /Тables /Сиstom Tables). } \\
\text { В таблице по вертикали установить вопрос } 4 \\
\text { (категории товаров, покупаемых в Интерне- } \\
\text { те), а по горизонтали - вопросы, характери- } \\
\text { зующие медиапредпочтения и медиаповеде- } \\
\text { ние респондентов. } \\
\text { В окне «Статистические критерии» устано- } \\
\text { вить флажок «Проверка независимости (кри- } \\
\text { терий Хи-квадрат)» }\end{array}$ & $\begin{array}{l}\text { - Табличная форма } \\
\text { (табл. 3) } \\
\text { - Выводы с про- } \\
\text { веркой гипотез в } \\
\text { табличной форме }\end{array}$ \\
\hline
\end{tabular}

Примечание: разработано автором.

Алгоритм разработки комплекса предложений по продвижению определенных категорий товаров в социальных сетях базируется на результатах третьего этапа. Последовательно описываются общее ядро медиапредпочтений и медиаповедения потребителей разных категорий товаров в социальных сетях, особен- 
Е.Б. Кметь, А.Е. Новикова. Методика исследования особенностей медиапредпочтений...

ности медиапредпочтений и медиаповедения потребителей разных категорий товаров в социальных сетях и портрет сегментов потребителей.

\section{Основная часть}

Результаты проверки (тестирования) методики представлены по итогам опроса респондентов по технологии CAWI, проведенного в апреле 2021 года. В качестве генеральной совокупности рассматривалось 95,6 млн человек в возрасте $12+$, которые хотя бы раз в месяц пользовались Интернетом в России. Размер детерминированной преднамеренной выборки составил 384 человека при уровне доверительной вероятности $95 \%$ и ошибке \pm 5 единиц.

Описательный (частотный) анализ вопросов анкеты показал следующее:

1. В качестве основного критерия сегментирования потребителей выбраны предпочтения к категориям товаров, приобретаемых в Интернете. Тройку лидирующих категорий товаров возглавляют одежда и обувь (19,8\% ответов респондентов), средства по уходу за собой набрали $18,1 \%$ ответов, товары для дома $-12,1 \%$. Однако в рейтинге интенсивности поиска информации о товарах лидируют средства по уходу за собой - 20,6\% ответов, второе место занимают одежда и обувь $19,3 \%$, а третье место у бытовой техники и электроники - 13,0\%. Интенсивность поиска вызвана повышенной заботой о безопасности, экологичности уходовой, декоративной косметики и средств для гигиены, а также уровнем цен и финансовым риском, связанным с приобретением бытовой техники и электроники.

2. Общая характеристика медиаповедения выглядит следующим образом: большинство респондентов $(59,8 \%)$ совершают покупки 1-2 раза в месяц; в качестве главной причины покупок в Интернете указывается возможность не посещать магазин (26,6\% ответов); 99,1\% пользуются социальными сетями и мессенджерами; $50 \%$ респондентов проводят в социальных сетях от 3 до 4 часов; среди основных причин использования социальных сетей указывают просмотр информационного, обучающего контента $(19,4 \%$ ответов) и общение с друзьями и знакомыми $(18,5 \%)$; большинству нравится размещать в социальных сетях личный контент, делиться своим опытом и мыслями (26,4\% ответов); чаще всего информацию о средствах по уходу за собой ищут в социальных сетях (20,6\% ответов); информацию о товарах ищут чаще в Инстаграм $(31,1 \%)$ и в YouTube $(21,1 \%)$.

3. Среди медиапредпочтений следует отметить, что большая часть покупок приходится на маркет-плейсы (83\% респондентов); 89,6\% респондентов активно ищут информацию о товарах в Интернете, а в качестве источника информации предпочитают полагаться на обзоры и посты блогеров (50\% респондентов); половина респондентов (49,1\% ответов) к рекламе относится нейтрально, не обращая на нее внимания, $21,7 \%$ ответов указывают на то, что она отвлекает от контента; половина респондентов (50\% ответов) считает, что реклама в социальных сетях скорее не влияет на решение о покупке товаров, чем влияет (неинтересные предложения или уже купленные товары, но иногда можно увидеть интересные предложения); тройку лидеров соцмедиа составляют Инстаграм (23,2\% ответов), Вконтакте $(17,1 \%)$ и YouTube $(16,9 \%)$. Однако среди соцмедиа, которые нравятся больше всего, второе место неожиданно достается Telegram (21,2\% ответов). Любимым типом контента в социальных сетях называют информационный по 
интересующим тематикам (35,7\% ответов), лидирующим форматом рекламырекламное видео в новостной ленте (22,7\% ответов), а лидирующим типом рекламы - информационный с описанием основных характеристик товара $(44,3 \%$ ответов).

Для проверки выдвинутых гипотез с целью выявления зависимости между предпочтениями приобретаемых товарных категорий и переменными, характеризующими медиапредпочтения и медиаповедение пользователей, используем коэффициент Хи-квадрата Пирсона $\left(\chi^{2}\right)$. Так как в анкете доминируют множественные вопросы с возможностью выбора нескольких вариантов ответа, для выявления зависимости между парами переменных следует использовать расчет показателя Хи-квадрата Пирсона. Однако вначале необходимо обратить внимание на статистическую значимость (вероятность наступления или ненаступления исследуемого события). Значение статистической значимости должно быть менее или равно 0,05 (5\%), что свидетельствует о значимой зависимости. Следовательно, с вероятностью 95\% можно утверждать: исследуемое событие произошло неслучайно и связано с какой-либо системой. Максимально значимой зависимости соответствует значение $\mathrm{P}<0,001$, очень значимой $-0,001<=\mathrm{p}<=0,0$.

Результаты значимости $p$ и значения Хи-квадрата Пирсона, свидетельствующие о наличии зависимости между категориями товаров, покупаемых в Интернете (вопрос 4), и медиапредпочтениями и медиаповедением потребителей в социальных сетях, представлены в табл. 3 .

Таблица 3

\section{Результаты значимости р и Хи-квадрата Пирсона, свидетельствующие о наличии зависимости между категориями товаров, покупаемых в Интернете (вопрос 4), и другими вопросами}

\begin{tabular}{|c|c|c|}
\hline Номер вопроса анкеты и его формулировка & $\begin{array}{c}\text { Значимость } \\
\text { p }\end{array}$ & $\begin{array}{l}\text { Хи-квадрат } \\
\text { Пирсона }\left(\chi^{2}\right)\end{array}$ \\
\hline \multicolumn{3}{|l|}{ Ядро медиаповедения } \\
\hline 2. Частота покупок товаров в Интернете & 0,292 & 60,233 \\
\hline 3. Причины покупок в Интернете & 0,000 & 158,890 \\
\hline 6. Использование социальных сетей и мессенджеров (да/нет) & 0,350 & 12,190 \\
\hline 9. Количество часов в день, проводимых в социальных сетях & 0,000 & 70,022 \\
\hline 10. Причины использования социальных сетей & 0,000 & 190,122 \\
\hline \multicolumn{3}{|l|}{ Особенности медиаповедения } \\
\hline $\begin{array}{l}\text { 11. Утверждения, характеризующие поведение в социальных } \\
\text { сетях }\end{array}$ & 0,000 & 164,269 \\
\hline 15. Активность поиска информации о товарах в Интернете & 0,000 & 249,354 \\
\hline $\begin{array}{l}\text { 16. Рейтинг социальных сетей как источника информации } \\
\text { о товарах }\end{array}$ & 0,102 & 117,269 \\
\hline
\end{tabular}


Е.Б. Кметь, А.Е. Новикова. Методика исследования особенностей медиапредпочтений...

\begin{tabular}{|c|c|c|}
\hline \multicolumn{3}{|c|}{ Окончание табл. 3} \\
\hline Номер вопроса анкеты и его формулировка & $\begin{array}{c}\text { Значимость } \\
\text { p }\end{array}$ & $\begin{array}{c}\text { Хи-квадрат } \\
\text { Пирсона }\left(\chi^{2}\right)\end{array}$ \\
\hline \multicolumn{3}{|l|}{ Ядро медиапредпочтений } \\
\hline 5. Площадки совершения покупок в Интернете & 0,027 & 36,415 \\
\hline 13. Ищут ли информацию о товарах в Интернете (да/нет) & 0,275 & 13,292 \\
\hline 14. Источник информации о товарах в социальных сетях & 0,361 & 23,747 \\
\hline 17. Отношение к рекламе в социальных сетях & 0,002 & 75,661 \\
\hline $\begin{array}{l}\text { 20. Сила влияния рекламы в социальных сетях на решение } \\
\text { о покупке товара }\end{array}$ & 0,001 & 63,676 \\
\hline \multicolumn{3}{|l|}{ Особенности медиапредпочтений } \\
\hline 7. Рейтинг используемых социальных сетей и мессенджеров & 0,000 & 205,696 \\
\hline 8. Рейтинг популярности социальных сетей и мессенджеров & 0,000 & 158,359 \\
\hline 12. Предпочитаемый тип контента & 0,001 & 109,463 \\
\hline 18. Предпочтительные форматы рекламы в социальных сетях & 0,000 & 154,871 \\
\hline 19. Предпочтительные типы рекламы в социальных сетях & 0,001 & 63,644 \\
\hline
\end{tabular}

Примечание: разработано авторами.

Значения Хи-квадрата Пирсона $\left(\chi^{2}\right)$, соответствующие значимой и сильной зависимости, в табл. 3 выделены темно-серым цветом, значимой и средней силы зависимости - светло-серым цветом. Представленные значения будут использованы для формулировки результатов проверки выдвинутых гипотез и реализации шагов 4.1 - 4.3 четвертого этапа процесса исследования особенностей медиапредпочтений и медиаповедения в социальных сетях потребителей разных категорий товаров.

Исследование гипотез демонстрирует следующие результаты:

H1: гипотеза полностью подтвердилась, показатели Хи-квадрата Пирсона значимы и демонстрируют более сильную взаимосвязь с категориями товаров для особенностей медиаповедения и медиапредпочтений, чем для ядра. Общую картину нарушают причины покупок в Интернете и причины использования социальных сетей, взаимосвязь которых с категориями товаров сильная, что говорит о необходимости отнести их к особенностям медиаповедения, а не ядру.

H2: гипотеза частично подтвердилась, частота покупок в Интернете, использование социальных сетей и мессенджеров, количество часов, проводимых в социальных сетях в день, не демонстрируют взаимосвязи с категориями товаров, однако причины покупок в Интернете и причины использования социальных сетей сильно взаимосвязаны с категориями товаров, поэтому их следует отнести к особенностям медиаповедения.

H3: гипотеза частично подтвердилась, утверждения, характеризующие поведение в социальных сетях, и активность поиска значимы и сильно взаимосвя- 
заны с категориями товаров, а рейтинг социальных сетей как источника информации о товарах следует отнести к ядру медиаповедения.

H4: гипотеза полностью подтвердилась, все параметры не связаны с категориями товаров либо имеют значимую, но слабую взаимосвязь.

H5: гипотеза полностью подтвердилась, все параметры обладают значимой и сильной взаимосвязью с категориями товаров.

Следовательно, окончательное распределение параметров по медиаповедению и медиапредпочтениям потребителей различных категорий товаров в социальных сетях должно выглядеть следующим образом:

Ядро медиаповедения описывают ответы на вопросы 2, 6, 9 и 16.

Особенности медиаповедения описывают частотные таблицы, построенные для категорий товаров (вопрос 4) и вопросов $3,10,11,15$.

Ядро медиапредпочтений описывают ответы на вопросы 5, 13, 14, 17 и 20.

Особенности медиапредпочтений описывают частотные таблицы, построенные для категорий товаров (вопрос 4) и вопросов 7, 8, 12, 18 и 19.

Далее рассмотрим ядро и особенности медиапредпочтений и медиаповедения потребителей разных категорий товаров в социальных сетях. В таблице 4 представлено описание ядра и особенностей медиаповедения и медиапредпочтений потребителей трех лидирующих категорий товаров по результатам опроса в социальных сетях.

\section{Таблица 4}

\section{Описание ядра и особенностей медиаповедения и медиапредпочтений} потребителей товаров в социальных сетях

\begin{tabular}{|c|c|c|c|}
\hline $\begin{array}{c}\text { Товарная } \\
\text { категория }\end{array}$ & Одежда и обувь & $\begin{array}{c}\text { Средства по уходу } \\
\text { за собой }\end{array}$ & Товары для дома \\
\hline \% ответов & 19,85 & 18,1 & 12,1 \\
\hline Вопросы & \multicolumn{3}{|l|}{ Ядро медиаповедения } \\
\hline $2,6,9,16$ & \multicolumn{3}{|c|}{$\begin{array}{l}\text { - 59,8\% респондентов совершают покупки в Интернете } 1-2 \text { раза в месяц; } \\
\text { - 99,1\% респондентов пользуются социальными сетями и мессенджерами; } \\
\text { - 50\% респондентов проводят в социальных сетях } 3-4 \text { часа ежедневно; } \\
\text { - тройку лидеров социальных сетей по поиску информации о товарах со- } \\
\text { ставляют Instagram (31,1\% ответов), YouTube }(21,1 \%) \text { и Вконтакте }(15,5 \%)\end{array}$} \\
\hline Вопросы & \multicolumn{3}{|c|}{ Особенности медиаповедения } \\
\hline $3,10,11,15$ & $\begin{array}{l}\text { - основная причина } \\
\text { покупки товаров в Ин- } \\
\text { тернете - не нужно по- } \\
\text { сещать магазин }(27,4 \% \\
\text { респондентов); } \\
\text { - основная причина } \\
\text { использования социаль- } \\
\text { ных сетей - просмотр } \\
\text { информационного, обу- } \\
\text { чающего контента } \\
(33,9 \%) ;\end{array}$ & & $\begin{array}{l}\text { - основная причина } \\
\text { покупки товаров в } \\
\text { Интернете - большое } \\
\text { количество скидок и } \\
\text { предложений }(15,1 \% \\
\text { респондентов); } \\
\text { - основная причина } \\
\text { использования соци- } \\
\text { альных сетей - обще- } \\
\text { ние с друзьями, зна- } \\
\text { комыми (17,9\%); }\end{array}$ \\
\hline
\end{tabular}


Е.Б. Кметь, А.Е. Новикова. Методика исследования особенностей медиапредпочтений...

Продолжение табл. 4

\begin{tabular}{|c|c|c|c|}
\hline $\begin{array}{c}\text { Товарная } \\
\text { категория }\end{array}$ & Одежда и обувь & $\begin{array}{c}\text { Средства по уходу } \\
\text { за собой }\end{array}$ & Товары для дома \\
\hline \% ответов & 19,85 & 18,1 & 12,1 \\
\hline & $\begin{array}{l}\text { - утверждение, описы- } \\
\text { вающее поведение: мне } \\
\text { нравится размещать в } \\
\text { социальных сетях лич- } \\
\text { ный контент, делиться } \\
\text { своим опытом и мысля- } \\
\text { ми (30,2\%); } \\
\text { - самой популярной } \\
\text { категорией товара, ин- } \\
\text { формацию о которой } \\
\text { ищут в социальных се- } \\
\text { тях, являются средства } \\
\text { по уходу за собой } \\
\text { (25,5\%) }\end{array}$ & $\begin{array}{l}\text { - основная причина } \\
\text { покупки товаров в Ин- } \\
\text { тернете - не нужно } \\
\text { посещать магазин } \\
\text { ( } 25,4 \% \text { респондентов); } \\
\text { - основная причина } \\
\text { использования соци- } \\
\text { альных сетей - про- } \\
\text { смотр информационно- } \\
\text { го, обучающего кон- } \\
\text { тента (28,3\%); } \\
\text { - утверждение, описы- } \\
\text { вающее поведение: мне } \\
\text { нравится размещать в } \\
\text { социальных сетях лич- } \\
\text { ный контент, делиться } \\
\text { своим опытом и мыс- } \\
\text { лями (28,3\%); } \\
\text { - самой популярной } \\
\text { категорией товара, } \\
\text { информацию о которой } \\
\text { ищут в социальных } \\
\text { сетях, являются сред- } \\
\text { ства по уходу за собой } \\
\text { (28,3\%) }\end{array}$ & $\begin{array}{l}\text { - утверждение, опи- } \\
\text { сывающее поведение: } \\
\text { мне нравится разме- } \\
\text { щать в социальных } \\
\text { сетях личный контент, } \\
\text { делиться своим опы- } \\
\text { том и мыслями } \\
(18,9 \%) ; \\
\text { - самой популярной } \\
\text { категорией товара, } \\
\text { информацию о кото- } \\
\text { рой ищут в социаль- } \\
\text { ных сетях, являются } \\
\text { одежда и обувь (17\%) }\end{array}$ \\
\hline Вопросы & \multicolumn{3}{|l|}{ Ядро медиапредпочтений } \\
\hline $5,13,14,17,20$ & \multicolumn{3}{|c|}{$\begin{array}{l}\text { - 83,0\% респондентов предпочитают покупать товары в маркет-плейсах } \\
\text { (Ozon, Wildberries и др.); } \\
\text { - 89,6\% респондентов ищут информацию о товарах в социальных сетях; } \\
\text { - самым популярным источником информации являются обзоры и посты } \\
\text { блогеров о товаре (50\% респондентов); } \\
\text { - 49,1\% респондентов относятся к рекламе в социальных сетях нейтраль- } \\
\text { но - не обращают внимания; } \\
\text { - 50\% респондентов считают, что реклама в социальных сетях скорее не } \\
\text { влияет на покупательское решение, чем наоборот: неинтересные предложе- } \\
\text { ния или уже купленные товары, хотя иногда можно встретить интересные } \\
\text { предложения }\end{array}$} \\
\hline Вопросы & \multicolumn{3}{|c|}{ Особенности медиапредпочтений } \\
\hline $7,8,12,18,19$ & $\begin{array}{l}\text { - самыми используемы- } \\
\text { ми являются Instagram } \\
(43,4 \%), \text { YouTube } \\
(42,5 \%) \text { и Вконтакте } \\
(31,1 \%) ;\end{array}$ & $\begin{array}{l}\text { - самыми используе- } \\
\text { мыми являются } \\
\text { Instagram }(39,6 \%) \text {, } \\
\text { YouTube }(30,2 \%) \text { и } \\
\text { Вконтакте }(29,2 \%) ;\end{array}$ & $\begin{array}{l}\text { - самыми используе- } \\
\text { мыми являются } \\
\text { Instagram }(24,5 \%) \text {, } \\
\text { YouTube }(23,9 \%) \text { и } \\
\text { Вконтакте }(18,9 \%) ;\end{array}$ \\
\hline
\end{tabular}


Окончание табл. 4

\begin{tabular}{|c|c|c|c|}
\hline $\begin{array}{c}\text { Товарная } \\
\text { категория }\end{array}$ & Одежда и обувь & $\begin{array}{c}\text { Средства по уходу } \\
\text { за собой }\end{array}$ & Товары для дома \\
\hline \multirow[t]{2}{*}{ \% ответов } & 19,85 & 18,1 & 12,1 \\
\hline & $\begin{array}{l}\text { - нравятся больше всего } \\
\text { Instagram }(39,6 \%), \\
\text { Telegram }(30,2 \%) \text { и } \\
\text { YouTube }(19,8 \%) ; \\
\text { - тип контента - развле- } \\
\text { кательный: юмор, мемы, } \\
\text { новости шоу-бизнеса } \\
\text { (30,2\%); } \\
\text { - предпочитаемый фор- } \\
\text { мат рекламы - реклам- } \\
\text { ное видео в новостной } \\
\text { ленте (23,6\%); } \\
\text { - предпочитаемый тип } \\
\text { рекламы - юмористиче- } \\
\text { ский, развлекательный } \\
\text { (17\%) }\end{array}$ & $\begin{array}{l}\text { - нравятся больше } \\
\text { всего Instagram (33\%), } \\
\text { Telegram }(26,4 \%) \text { и } \\
\text { YouTube }(17,9 \%) ; \\
\text { - тип контента - ин- } \\
\text { формационный (по } \\
\text { интересующим тема- } \\
\text { тикам) (29,4\%); } \\
\text { - предпочитаемый } \\
\text { формат рекламы - } \\
\text { рекламное видео в } \\
\text { новостной ленте } \\
\text { (25,4\%); } \\
\text { - предпочитаемый тип } \\
\text { рекламы - информа- } \\
\text { ционный с описанием } \\
\text { основных характери- } \\
\text { стик товара (20,8\%) }\end{array}$ & $\begin{array}{l}\text { - нравятся больше } \\
\text { всего Instagram } \\
(22,6 \%), \text { Telegram } \\
(17,9 \%) \text { и YouTube } \\
(14,2 \%) ; \\
\text { - тип контента - ин- } \\
\text { формационный (по } \\
\text { интересующим тема- } \\
\text { тикам) (16\%); } \\
\text { - предпочитаемый } \\
\text { формат рекламы - } \\
\text { прямая реклама у бло- } \\
\text { геров в социальных } \\
\text { сетях (13,2\%); } \\
\text { - предпочитаемый тип } \\
\text { рекламы - юмористи- } \\
\text { ческий, развлекатель- } \\
\text { ный (12,3\%) }\end{array}$ \\
\hline
\end{tabular}

Примечание: разработано авторами.

Следует отметить, что в табл. 4 представлены только лидирующие ответы, причем для ядра медиапредпочтений и медиаповедения они являются общими для всех пользователей, а в особенностях определены в разрезе потребителей определённых категорий товаров.

\section{Выводы и научная новизна}

Тестирование предлагаемой методики, проведенное по результатам опроса, демонстрирует, что в медиаповедении и медиапредпочтениях пользователей в социальных сетях присутствуют как общие черты, так и особенности, свойственные потребителям определенных категорий товаров. Исследование выдвинутых гипотез позволило пересмотреть и уточнить перечень параметров, составляющих ядро и особенности медиаповедения и медиапредпочтений в социальных сетях.

Научная новизна исследования заключается не только в теоретическом анализе и эмпирической проверке содержания медиаисследований потребителей различных категорий товаров в социальных сетях, но и в уточнении параметров, составляющих ядро и особенности их медиаповедения и медиапредпочтений.

Методика исследования особенностей медиаповедения и медиапредпочтений в социальных сетях потребителей различных категорий товаров позволяет бизнесу разработать эффективные мероприятия по поддержанию спроса на товары и формированию лояльности к компании, бренду и продуктам. 
Тем не менее, важно отметить и некоторые ограничения практического использования методики. Например, исследования с целью отслеживания траекторий развития поведения потребителей в соцмедиа необходимо проводить с определенной периодичностью (один, а лучше два раза в год), что требует некоторых затрат и усилий. Следовательно, сотрудники предприятия должны обладать необходимыми практическими навыками и умениями для проведения подобных исследований.

1. Жилавская И.В. Медиаповедение молодежной аудитории в условиях дивергенции // Медиа. Информация. Коммуникация. - 2012. - № 1. - С. 28-30.

2. Кметь Е.Б. Маркетинговые коммуникации. Теория, практика, управление: учебник для магистров. - Саратов: Ай Пи Эр Медиа, 2016. - 183 с.

3. Кметь Е.Б. Методика исследования медиапредпочтений целевой аудитории: полное погружение // Экономика и предпринимательство. - 2014. - № 12-3 (53). - С. 919-923.

4. Кметь Е.Б., Ким А.Г. Управление маркетингом: учебник.- Владивосток: Изд-во ВГУЭС, 2015. $-308 \mathrm{c}$.

5. Alalwan A.A. Investigating the impact of social media advertising features on customer purchase intention // International Journal of Information Management. - 2018. - № 42. P. 65-77. - URL: https://doi.org/10.1016/j.ijinfomgt.2018.06.001

6. Arrigo E., Liberati C. \& Mariani P. Social Media Data and Users' Preferences: A Statistical Analysis to Support Marketing Communication // Big Data Research. - 2021. - № 24. https://doi.org/10.1016/j.bdr.2021.100189

7. Customer engagement behaviours in social media: capturing innovation opportunities / J. Carlson, M. Rahman, R. Voola, N. De Vries // Journal of Services Marketing. - 2018. № 32 (1). - P. 83-94. - URL: https://doi.org/10.1108/JSM-02-2017-0059

8. Dodoo N.A., \& Wu L. Exploring the anteceding impact of personalised social media advertising on online impulse buying tendency // International Journal of Internet Marketing and Advertising. - 2019. - № 13(1). - P 73-95. - URL:http://dx.doi.org/10.1504/IJIMA. 2019.10019167

9. Setting the future of digital and social media marketing research: Perspectives and research propositions / Y.K. Dwivedi, E. Ismagilova, D.L. Hughes [et. al.] // International Journal of Information Management Available online.- 2020. - № 7.- P. 1-37. - URL: https://doi.org/10.1016/j.ijinfomgt.2020.102168

10. Passive and Active Social Media Use and Depressive Symptoms among United States Adults / C. G. Escobar-Viera, A. Shensa, N.D. Bowman [et. al.] // Cyberpsychology, Behavior, and Social Networking. - 2018. - № 21. - P. 437-443. - URL: https://doi.org/10.1089/cyber.2017.0668

11. Gross M. Watching two billion people // Current biolog. - 2018. - № 9(28). - P. 527530. - URL: https://doi.org/10.1016/j.cub.2018.04.065

12. Jacobson J., Gruzd A., Hernández-García A. Social media marketing: Who is watching the watchers? // Journal of Retailing and Consumer Services. - 2020. - № 53. - P. 1-12. URL: ttps://doi.org/10.1016/j.jretconser.2019.03.001

13. Behavioral implications of international social media advertising: An investigation of intervening and contingency factors / W.J. Johnston, S. Khalil, A.N.H. Le [et al.] // Journal of International Marketing. - 2018. - № 26(2). - P. 43-61. - URL: https://doi.org/10.1509\%2Fjim.16.0125 
14. Kaye L.K. Exploring the "socialness" of social media // Computers in Human Behavior Reports. - 2021. - № 3. - URL: https://doi.org/10.1016/j.chbr.2021.100083

15. Meler A., Reinecke L. Computer-Mediated Communication, Social Media, and Mental Health: A Conceptual and Empirical Meta-Review // Communication Research. - 2020. № 1-72. - URL: https://doi.org/10.1177\%2F0093650220958224

16. Investigating users' experience on social media ads: perceptions of young users / D.A. Qudah, B. Al-Shboul, A. Al-Zoubi // Heliyon. - 2020. - № 6 (7). - URL: https://doi.org/10.1016/j.heliyon.2020.e04378.

17. Tran T.P. Personalized ads on Facebook: An effective marketing tool for online marketers // Journal of Retailing and Consumer Services. - 2017. - № 39. - P. 230-242. - URL: https://doi.org/10.1016/j.jretconser.2017.06.010

18. The Reciprocal Relationship Between Passive Social Networking Site (SNS) Usage and Users' Subjective Well-Being / J.L. Wang, J. Gaskin, D.H. Rost, D.A. Gentile // Social Science Computer Review. - 2018. - № 36 (5). - P. 511-522. - URL: https://doi.org/10.1177\%2F0894439317721981

\section{Транслитерация}

1. Zhilavskaya I.V. Mediapovedenie molodezhnoj auditorii v usloviyah divergencii // Media. Informaciya. Kommunikaciya. - 2012. - № 1. - S. 28-30.

2. Kmet' E.B. Marketingovye kommunikacii. Teoriya, praktika, upravlenie: uchebnik dlya magistrov. - Saratov: Aj Pi Er Media, 2016. - 183 s.

3. Kmet' E.B. Metodika issledovaniya mediapredpochtenij celevoj auditorii: polnoe pogruzhenie // Ekonomika i predprinimatel'stvo. - 2014. - № 12-3 (53). - S. 919-923.

4. Kmet' E.B., Kim A.G. Upravlenie marketingom: uchebnik. - Vladivostok: Izd-vo VGUES, 2015. $-308 \mathrm{~s}$.

(C) Е.Б. Кметь, 2021

() А.Е. Новикова, 2021

Для цитирования: Кметь Е.Б., Новикова А. Е. Методика исследования особенностей медиапредпочтений и медиаповедения в социальных сетях потребителей разных категорий товаров // Территория новых возможностей. Вестник Владивостокского государственного университета экономики и сервиса. - 2021. - Т. 13, № 2. - С. 7-22.

For citation: Kmet E. B., Novikova A.E. Methodology for researching the characteristics of media preferences and media behavior in social networks of consumers of different categories of goods, The Territory of New Opportunities. The Herald of Vladivostok State University of Economics and Service, 2021, Vol. 13, № 2, pp. 7-22.

DOI https://doi.org/10.24866/VVSU/2073-3984/2021-2/007-022

Дата поступления: 14.05.2021. 